\title{
Heterogeneous Agents, Human Capital Formation and International Income Inequality*
}

\author{
Haris Munandar ${ }^{\dagger}$ \\ Tinbergen Institute \\ Erasmus University Rotterdam
}

\author{
Jean-Marie Viaene $\ddagger$ \\ Tinbergen Institute \\ Erasmus University Rotterdam \\ CESifo
}

July 2006

\begin{abstract}
The paper examines the effect of heterogeneity in individual human capital formation on cross-country income inequality. It considers a two-country model of overlapping generation heterogeneous economies with the following features: (1) individuals are heterogeneous with respect to inborn ability and parental human capital; (2) intergenerational transfers take place via public investment in education financed by tax, and parental education; (3) due to variation in individual human capital, we have endogenous heterogeneity both in labor supply and in parents' participation in self-educating their offspring. Besides exploring cross-country variation in public education, how its low level can lead to a poverty trap and how its high level can result in an increasing society's effective human capital, we study the effects of capital markets integration, in equilibrium, on the intra-generational income inequality in both the investing and receiving countries.
\end{abstract}

Keywords: Heterogenous Agents, Human Capital, Poverty Trap, Income Inequality.

JEL Classification: D91, E25, H52.

${ }^{*}$ We thank Harry Bowen, Dick van Dijk, Joe Francois, participants of the CEPR-TI Research Workshop on Trade, Industrialization and Development 2006 (Rotterdam) and seminar participants at Erasmus University and Tinbergen Institute for helpful comments and suggestions.

†Tinbergen Institute, Erasmus University Rotterdam, P.O. Box 1738, NL-3000 DR Rotterdam, The Netherlands, e-mail: munandar@few.eur.nl (corresponding author)

$\ddagger$ Tinbergen Institute, Erasmus University Rotterdam, P.O. Box 1738, NL-3000 DR Rotterdam, The Netherlands, e-mail: viaene@few.eur.nl 


\section{Introduction}

Social mobility and persistent inequality are two issues that assume considerable importance from both theoretical and policy-making perspectives. The questions of how families can climb the ladder of social and economic status and what determines their income are interesting and important. Also, the inquiries of what establishes income inequality in equilibrium and why it differs across countries remain challenging and crucial. The traditional explanations include cross country differences in technological progress and asymmetric impacts of globalization of world trade and financial markets. Nonetheless, conventional wisdom dictates us that an attempt to provide explanation concerning both issues simultaneously must place education into the center stage. This chapter adopts this view and focuses on the process of human capital formation to examine the above issues.

Various international organizations compile extensive lists of indicators that compare schooling accomplishments across countries. A primary characteristic of these indicators is that formal education, parental tutoring and other ways of acquisition of knowledge take place differently in various parts of the world. The level and efficiency of public education, the contribution of parents and the utilization of current technology differ across economies and the variation can be enormous. If we accept that processes describing the human capital formation influence economic output and income distribution, then we need to formalize such processes to find out how they may be significant.

A large literature has improved our understanding of the determinants of earning inequality. Atkinson (1999), Corneo and Jeanne (2001) show that social norms are crucial determinants of income distribution. Various studies have been conducted to analyze the role of human capital accumulation on income distribution in various contexts. [see, e.g. Benabou (1996), Chiu (1998), Fernandez and Rogerson (1998) and Acemoglu (2003)].

There are numerous literatures linking the components of education and differences in income distribution. Becker and Chiswick (1966) demonstrate that income inequality is positively correlated with the schooling inequality and negatively correlated with schooling level. Based on data from nine countries, Chiswick (1971) claims that earning inequality increases with educational inequality. Moreover, us- 
ing larger sample countries, Adelman and Morris (1973) and Chenery and Syrquin (1975) show that higher levels of schooling reduce income inequality. However, recent progress in technology do not affect the formation of human capital in various countries in similar fashion. Our model differentiate between cross-country technological variation which affect mostly home education vs. technological differences which affect mainly public education.

We analyze an overlapping generations economy that produces a single good using two types of production factors: physical capital, and human capital represented by an interaction between labor supply and a continuum of skills. Each individual lives for three periods, where during the 'childhood' time (in which no economic decision is made) education is obtained. Intergenerational transfers in the economy occur via two channels: (1) the provision of public education financed by labor income tax and (2) the investments made by parents in tutoring their own children at home. Additionally, every child is endowed with a random inborn ability.

A government has two roles in the economy: first, in providing public education budget by taxing wage incomes and, second, in conducting public education itself and determining its level. Public education may consist of formal education in schools and expenditure related to schooling (e.g. public library and media). However, in our framework, the level of public education represents the effective educational inputs related to teaching and not to other public education expenditures.

Home education is provided by the immediate family and performed mainly through parental coaching, social interaction and learning technology available at home (e.g. books and internet). In this case, the level of human capital of parents and the time they devote to tutoring are essential factors.

Various economic models have constructed similar mechanisms to describe human capital formation. Such processes usually concentrate on very few parameters to maintain tractability. ${ }^{1}$ In our model the human capital formation process displays a few important properties. First, individuals from above-average human capital families have a lower return to investment in public education than those from belowaverage families. Also, the cost of attaining a particular human capital level for the younger generation is smaller for families endowed with relatively higher levels

\footnotetext{
${ }^{1}$ For example, see e.g., Eckstein and Zilcha (1994), Orazem and Tesfatsion (1997) and Hanushek (2002).
} 
of human capital. Other models exhibiting these features include Tamura (1991) and Fischer and Serra (1996). Second, the significance of parental human capital in shaping the human capital of an offspring has been developed. Burnhill et al. (1990) show that the education level of parents affects entry to higher education more that the influence of the social class of them. More recently, Barro and Lee (2001) and Brunello and Checchi (2005) discover that family characteristics, including parental education, improve student's achievement. A reason that is offered is that the level of education of parents contributes to the quality of parental involvement at home. ${ }^{2}$

When analyzing the effect of capital markets integration we consider two economies, one capital exporting and the other capital importing. This setting leads to postintegration equalization of returns to capital. There are previous literatures dealing with differences in cross-country returns to capital, for instance Lucas (1990) and Leidierman and Razin (1994). Notably, Viaene and Zilcha (2002) show the theoretical allocation of world output among countries following capital markets integration and its consequences on income distribution. However, our model seems to be more realistic since we allow for the different roles between the parental and public education and also incorporates a widely observed elastic labor supply across families. ${ }^{3}$

Using our model we demonstrate that usual explanatory factors of income inequality like physical capital mobility and technological progress in production play no role in our model in determining income distribution in equilibrium. Initial condition on stock of human capital is relevant in the sense that a country that starts from a higher level of human capital, not necessarily more equal, has a better chance to experience more equality over time. But, physical capital mobility resulted from this gap in endowments do not affect the income inequality following capital markets integration although the effects on welfare can be substantial. These findings isolate processes of human capital formation as the main source of discrepancy in income inequality. Such result stands in contrast with those of Viaene and Zilcha (2002) which suggest that following capital markets integration, inequality in intragenerational income distributions changes in all dates. This difference exists because they assume the existence of intergenerational transfer of physical capital (bequest).

\footnotetext{
${ }^{2}$ For more discussions see Hanushek (1986) and Glaeser (1994).

${ }^{3}$ Wharton and Blair-Loy (2006) provides empirical evidence on the relationship between work hours and family life in the United States, London, and Hong Kong.
} 
However, the empirical evidence seems to suggest that among families, bequests are far from universal (see Laitner, 1997).

Our model implies the following features to hold in equilibrium: (a) utility maximization leads to endogenous labor supply; (b) it allows some parents not to participate to the education of their own child, which is a stylized fact of some economies; (c) under a certain condition, the choice of public education determines whether poverty trap exists; (d) increasing the provision of public education will reduce income inequality.

With the model we also demonstrate that when government plays no role in the education process (i.e., zero provision of public education), our economy generates an endogenously determined intragenerational income distribution. In this case, inequality emerges from both the random inborn ability and the differences in parents' human capital. The role of education here is to dampen the variation emerging from families' human capital and therefore lower the inequality of both human capital and income distributions. In other words, if one compares two economies that differ in public education provision only, the economy that invests more in public education faces lower income inequality along the whole equilibrium path. In particular, when the level of public education is very low, the economy may enter a poverty trap, that is, a decrease of stock of human capital over time. Contrary to this situation, higher levels of public education guarantee that the aggregate human capital increases over time.

On the other hand, the heterogeneity in parents' human capital generates a certain pattern of heterogeneity in children's labor supply. In particular, the lower the level of human capital of parents, the higher the labor supply exerted by the corresponding offspring in the next period. Again, we also find that such feature does not affect intragenerational income inequality, even after capital markets integration.

In this work, technological improvement for education matters. It has the opposite effects on inequality depending on whether such improvement occurs in the public education or in the home education. Specifically, a more efficient public education decrease inequality while a more efficient home tutoring rises inequality.

The remainder of the chapter is arranged as follows. Section 2 elaborates an Overlapping Generation Model with heterogenous agents and analyzes the properties of the model, including equilibrium conditions, future income, role of parents, 
poverty trap and variation of labor supply. Section 3 explains the capital markets integration with its implication to wage rates of domestic and foreign economies. Section 4 analyzes the impacts of human capital formation on various facets of income inequality, including the roles of public education, initial endowments and education technology. Section 5 calibrates our dynamic general equilibrium model using data from the Netherlands over the period 1975-2000. A numerical simulation computes the response of income inequality to various processes of human capital formation and confirms the results of the previous section. Section 6 concludes. To facilitate the reading we relegate all proofs to the Appendix.

\section{Human capital formation}

\subsection{Preferences and technology}

Consider an overlapping generations economy with no population growth in which continuum of individuals live for three periods. During the first period, children obtain education but do not involve in any economic decision making. After finishing school, they become economically active during the next two periods, a working period followed by a retirement period. At the end of the first period, every individual gives birth to one offspring. Indicate by $G_{t}$ the set of individuals born at the beginning of period $t-1$ and refer to these individuals as generation $t$. Denote the set of families in each generation by $\Omega=[0,1]$ and the Lebesgue measure on $\Omega$ by $\mu$. Each individual in $G_{t}$ is characterized by its family name $\omega \in \Omega$.

In this economy, agents are endowed with two units of time that can be allocated to labor, leisure and self-educating the offspring. Parents care about the welfare of the children. More specifically, we assume that parents, during their working period, derive utility from the future income of the children. Labor is elastic and hence each family's supply of labor and human capital is the result of utility maximization. ${ }^{4}$ Let $l_{t}(\omega)$ and $h_{t}(\omega)$ the levels of labor supply and human capital respectively, of individual $\omega \in G_{t}$.

We model the production of human capital consisting of two components: informal education initiated and provided by parents at home, public education provided

\footnotetext{
${ }^{4}$ This setting is a generalization of Viaene and Zilcha (2003) which assumes that each family supplies one unit labor inelastically.
} 
by the government by, for example, constructing schools and employing teachers. The parental education depends on the time spent by the parents to this purpose, indicated by $e_{t}(\omega)$ and the quality of parental guidance represented by human capital level of the parents, $h_{t}(\omega)$. The level of public education is denoted by $e_{g t}$. The labor supply and human capital of the teachers determine the quality of public education, and hence the formation of new generation's human capital. We assume that instructors in each generation are selected randomly from the population of that generation. We also assume that the random inborn ability of child $\omega \in G_{t}$, expressed as $\theta_{t}(\omega)$, is known already when parents make decisions about labor supply and parental tutoring. Moreover, all the random variables $\theta_{t}(\omega)$ are independent and identically distributed with values in $[\underline{\theta}, \bar{\theta}]$, where $0<\underline{\theta}<\bar{\theta}<\infty$, and denote its mean by $\hat{\theta}$ and define, without loss of generality, $\hat{\theta}=1$. We assume that for some parameters $\beta_{1}>1, \beta_{2}>1, v>0$ and $\eta>0$, the evolution process of the human capital of each family $\omega \in G_{t+1}$ is given as follows:

$$
h_{t+1}(\omega)=\theta_{t}(\omega)\left[\beta_{1} e_{t}(\omega) h_{t}^{v}(\omega)+\beta_{2} e_{g t} \bar{l}_{t} \bar{h}_{t}^{\eta}\right]
$$

where the labor supply and human capital involved in public schooling, denoted by $\overline{l_{t}}$ and $\overline{h_{t}}$ respectively, are the average/aggregate labor supply and average/aggregate human capital of generation $t$. The constants $\beta_{1}$ and $\beta_{2}$ represent the efficiencies of parental and public education in contributing to human capital. $\beta_{1}$ is affected by the home environment, family size and interaction among family members while $\beta_{2}$ is influenced by the schooling system, facilities, size of classes, social interaction, and so forth. The parameters $v$ and $\eta$ indicates the externalities derived from parents' and society's human capital respectively. Empirical support for (1) is abundant, for example Brunello and Checchi (2005) who demonstrate the importance of both home and public education in human capital formation using Italian data.

The human capital formation given by (1) exhibits the characteristics that public education smooths the family attributes. As it is widely observed, individuals from poor family have a greater return to human capital derived from public schooling than those born to above-average human capital families. In this setting, the representation of private and public inputs in the production of human capital is through allocation of time. It is argued that the learning time, together with the 
human capital of instructors, should be the relevant variables in such a process. This is in line with Hanusek (2002) who suggests that considering the efficiency in the provision of public education is more relevant than focusing on the expenditure of public education. This difference is crucial since in the dynamic framework the cost of producing a particular level of human capital varies with relative factor price.

Consider $y_{t}(\omega)$ as the lifetime income of individual $\omega \in G_{t}$, which is earned in the second period. As it is common to all, individual income is determined by the effective human capital, that is the interaction of the labor supply and the human capital. Suppose $w_{t}$ is the wage rate per effective human capital in period $t$ and $\tau_{t}$ is the tax rate on labor income, then

$$
y_{t}(\omega)=w_{t}\left(1-\tau_{t}\right) l_{t}(\omega) h_{t}(\omega)
$$

We assume the existence of public education regime such that the taxes on incomes are used to finance public education costs of the young generation. Using (1) and (2), balanced government budget implies the equality of public education expenditure with tax income,

$$
\int_{\Omega} w_{t} e_{g t} \bar{l}_{t} \bar{h}_{t} d \mu(\omega)=\int_{\Omega} \tau_{t} w_{t} l_{t}(\omega) h_{t}(\omega) d \mu(\omega)
$$

and equivalently,

$$
e_{g t}=\tau_{t}
$$

that is, the proportion of the economy's labor supply used for public education is equal to the tax rate on labor. ${ }^{5}$

Production in this economy is carried out by competitive firms that produce a single commodity, using physical capital and effective human capital. This commodity is both consumed and used as production input. There is a full depreciation of physical capital, $K_{t}$. The per-capita effective human capital in date $t, \bar{l}_{t} \bar{h}_{t}$, is an input in the aggregate production process. In particular we take the per-capita production function to be:

$$
q_{t}=F\left(K_{t},\left(1-e_{g t}\right) \bar{l}_{t} \bar{h}_{t}\right)
$$

\footnotetext{
${ }^{5}$ Here we assume that $l_{t}(\omega)$ and $h_{t}(\omega)$ are independent as $h_{t}(\omega)$ depends only on primitives at $t-1$ through human capital production function (1). A weaker condition would result in $e_{g t}=b_{t} \tau_{t}$ with $b_{t}=\frac{\int_{\Omega} l_{t}(\omega) h_{t}(\omega) d \mu(\omega)}{\bar{l}_{t} \bar{h}_{t}}$, which does not change subsequent qualitative results.
} 
Moreover, $F(\cdot, \cdot)$ is assumed to exhibit constant returns to scale, it is strictly increasing, concave, continuously differentiable and satisfies $F_{K}\left(0,\left(1-e_{g t}\right) \bar{l}_{t} \bar{h}_{t}\right)=\infty$, $F_{H}\left(K_{t}, 0\right)=\infty$ and $F\left(0,\left(1-e_{g t}\right) \bar{l}_{t} \bar{h}_{t}\right)=F\left(K_{t}, 0\right)=0$.

\subsection{Competitive equilibrium}

In this chapter we assume that the political process which determines the levels of public provision of education is exogenous. The subsequent analysis, however, does not depend on these positive public education level, $e_{g t}$. In other words, if $\left\{e_{g}\right\}_{t=0}^{\infty}$ is determined by some social welfare function maximization all the results hold.

At time $t$, given the level of public education provision $e_{g t}$, agent $\omega$ maximizes lifetime utility, which depends on consumption, labor supply, leisure and income of the children, so as to maximize

$$
\max _{e_{t}, s_{t}, l_{t}} u_{t}(\omega)=c_{1 t}(\omega)^{\alpha_{1}} c_{2 t}(\omega)^{\alpha_{2}} y_{t+1}(\omega)^{\alpha_{3}}\left[2-l_{t}(\omega)-e_{t}(\omega)\right]^{\alpha_{4}}
$$

subject to constraints

$$
\begin{gathered}
c_{1 t}(\omega)=y_{t}(\omega)-s_{t}(\omega) \geq 0, \\
c_{2 t}(\omega)=\left(1+r_{t+1}\right) s_{t}(\omega),
\end{gathered}
$$

where $h_{t+1}$ and $y_{t+1}$ are defined by (1) and (2). The $\alpha_{i}$ 's are known intensity parameters and $\alpha_{i}>0$ for $i=1,2,3,4$. The $c_{1 t}$ and $c_{2 t}$ denote, respectively, consumption in first and second period of agent's economically active life. Implicitly we assume that $c_{1}$ covers consumption of children in the family. Savings is represented by $s_{t}(\omega)$ while labor supply is indicated by $l_{t}(\omega)$. Leisure is given by $\left[2-l_{t}(\omega)-e_{t}(\omega)\right]$. The interest factor at date $t$ is $1+r_{t+1}$. The children's income $y_{t+1}(\omega)$ enters parents' utility function directly and represents the motivation for parents' investment in tutoring.

Given some tax rates $\left(\tau_{t}\right)$, the initial physical capital $k_{0}$ and the initial distributions of labor supply $l_{0}(\omega)$ and of human capital $h_{0}(\omega)$, a competitive equilibrium is $\left\{l_{t}(\omega), e_{t}(\omega), s_{t}(\omega), K_{t} ; w_{t}, r_{t}\right\}$ such that for all $t$ and all individuals $\omega \in G_{t}$, $\left\{l_{t}(\omega), e_{t}(\omega)\right.$ and $\left.s_{t}(\omega)\right\}$ are the solution to the above problem given $\left\{w_{t}, r_{t}\right\}$. In the equilibrium, the following market clearing conditions hold:

$$
w_{t}=F_{H}\left(K_{t},\left(1-e_{g t}\right) \bar{l}_{t} \bar{h}_{t}\right),
$$




$$
\begin{gathered}
1+r_{t}=F_{K}\left(K_{t},\left(1-e_{g t}\right) \bar{l}_{t} \bar{h}_{t}\right) \\
K_{t+1}=\int_{\Omega} s_{t}(\omega) d \mu(\omega)
\end{gathered}
$$

Equations (8) and (9) are clearing conditions on factor markets. Equation (10) is a clearing condition for physical capital, equating aggregate savings at time $t$ with the aggregate capital stock at date $t+1$. The first order conditions that are necessary and sufficient for an optimum are:

$$
\frac{\alpha_{4}}{2-l_{t}(\omega)-e_{t}(\omega)}=\frac{\beta_{1} \alpha_{3}\left(1-\tau_{t+1}\right) w_{t+1} l_{t+1}(\omega) h_{t}^{v}(\omega) \theta_{t}(\omega)}{y_{t+1}}, \quad \text { if } \quad e_{t}(\omega)>0
$$

$$
\geq, \quad \text { if } \quad e_{t}(\omega)=0
$$

Equation (12) optimally divides the unit of time into labor supply, leisure and the time spent on tutoring by the parents. Equation (13) takes care the situation in which individuals derive a negative marginal utility from spending time educating their children. Such individuals would use their time instead either to enjoy leisure or to work or both.

Assuming that the externality of individual labor supply to society public education is negligible, ${ }^{6}$ we also have the following first order condition:

$$
\frac{\alpha_{4}}{2-l_{t}(\omega)-e_{t}(\omega)}=\frac{\alpha_{1} w_{t}\left(1-\tau_{t}\right) h_{t}(\omega)}{c_{1 t}(\omega)}
$$

From (6), (7) and (11) we obtain:

$$
c_{1 t}(\omega)=\left[\frac{\alpha_{1}}{\alpha_{1}+\alpha_{2}}\right] y_{t}(\omega)
$$

and combining (6) and (15) we have:

$$
s_{t}(\omega)=\left[\frac{\alpha_{2}}{\alpha_{1}+\alpha_{2}}\right] y_{t}(\omega)
$$

\footnotetext{
${ }^{6}$ Note that in our human capital production function (1), society public education depends on the average labor supply. In the limit, the contribution of each individual labor supply to the average is negligible.
} 
which allocate present income into current consumption and savings based on the intensities of both consumptions in the utility function.

Whenever $e_{t}(\omega)>0$, using (2) and (15), we can rewrite (14) as follows:

$$
l_{t}(\omega)=\left[\frac{\alpha_{1}+\alpha_{2}}{\alpha_{1}+\alpha_{2}+\alpha_{4}}\right]\left(2-e_{t}(\omega)\right)
$$

and using (1), (2), (3) and (12), we obtain:

$$
e_{t}(\omega)=\frac{\alpha_{3}}{\alpha_{3}+\alpha_{4}}\left[2-l_{t}(\omega)-\frac{\alpha_{4} \beta_{2}}{\alpha_{3} \beta_{1}} \frac{\tau_{t} \bar{l}_{t} \bar{h}_{t}^{\eta}}{h_{t}^{v}(\omega)}\right]
$$

After substituting (17) into (18) we have:

$$
e_{t}(\omega)=\frac{1}{\alpha_{1}+\alpha_{2}+\alpha_{3}+\alpha_{4}}\left[2 \alpha_{3}-\left(\alpha_{1}+\alpha_{2}+\alpha_{4}\right) \frac{\beta_{2}}{\beta_{1}} \frac{\tau_{t} \bar{l}_{t} \bar{h}_{t}^{\eta}}{h_{t}^{v}(\omega)}\right]
$$

Therefore, $e_{t}(\omega)$ increases with the parents' human capital $h_{t}(\omega)$ but decreases with the tax rate $\tau_{t}$. The higher the human capital level of parents, the lower the return to public education, and hence in optimum parents will dedicate more time to tutor their children. The higher the tax rate, the higher the return to public education and hence the more optimal for parents to devote less time in educating their children. Also, $e_{t}(\omega)$ decreases with the intensities of consumptions, $\alpha_{1}$ and $\alpha_{2}$. If current or future consumption is more important, then more time will be allocated for working which implies more income, and less time for tutoring offspring. As expected, higher relative importance on leisure in parents' utility $\alpha_{4}$ decreases tutoring time $e_{t}(\omega)$ as well. Note that intensities of consumption play no role in a model with inelastic labor supply since the parental tutoring time has no income effect for working generation (see Viaene and Zilcha, 2003).

Moreover, substituting (19) into (17) results in:

$$
l_{t}(\omega)=\left[\frac{\alpha_{1}+\alpha_{2}}{\alpha_{1}+\alpha_{2}+\alpha_{3}+\alpha_{4}}\right]\left[2+\frac{\beta_{2} \tau_{t} \bar{l}_{t} \bar{h}_{t}^{\eta}}{\beta_{1} h_{t}^{v}(\omega)}\right]
$$

that is, $l_{t}(\omega)$ increases with the tax rate $\tau_{t}$ but decreases with the parents' human capital $h_{t}(\omega) .{ }^{7}$ A higher tax rate lower income in (2) which is then compensated by high labor. Parents with high human capital exert less labor and spend time more

\footnotetext{
${ }^{7}$ The contribution of individual labor supply to society labor supply is negligible due to the continuum nature of individuals.
} 
to educate their children or to enjoy leisure. High values attached to consumptions (i.e., high $\alpha_{1}$ and $\alpha_{2}$ ) induce people to work more.

However, when $e_{t}(\omega)=0$, from (17) we simply have:

$$
l_{t}(\omega)=\frac{2\left(\alpha_{1}+\alpha_{2}\right)}{\alpha_{1}+\alpha_{2}+\alpha_{4}}
$$

suggesting that labor supply increases with intensities of consumptions, decreases with importance of leisure and independent of the share of children's expected incomes in the utility function.

\subsection{Income at the future date}

It is important to note that $e_{t}(\omega)$ in $(19)$ and $l_{t}(\omega)$ in (20) are independent of the inborn ability of their offspring. Using the result from previous subsection, we develop an expression of income at date $t+1, y_{t+1}(\omega)$. To achieve this, we apply (12) and (13) and make use of (1), (2) and (3) to obtain:

$$
y_{t+1}(\omega)=\left(1-\tau_{t+1}\right) w_{t+1} l_{t+1}(\omega) h_{t+1}(\omega)
$$

where,

$$
h_{t+1}(\omega)=\left[\frac{\alpha_{3}}{\alpha_{1}+\alpha_{2}+\alpha_{3}+\alpha_{4}}\right] \theta_{t}(\omega)\left[2 \beta_{1} h_{t}^{v}(\omega)+\beta_{2} \tau_{t} \bar{l}_{t} \bar{h}_{t}^{\eta}\right]
$$

whenever $e_{t}(\omega)>0$, and

$$
h_{t+1}(\omega)=\beta_{2} \theta_{t}(\omega) \tau_{t} \bar{l}_{t} \bar{h}_{t}^{\eta}
$$

if $e_{t}(\omega)=0$.

Expressions (22)-(24) show the individual income at the future date in terms of the wage rate at date $t+1$, the parents' human capital, the current public education input $\left(\tau_{t}=e_{g t}\right)$, the society's levels of labor supply and human capital at date $t$ and the externalities in education. When $e_{t}(\omega)>0$, an increase in any of these variables results in a higher income of the future generation. Also, the more parents care about their children (i.e., higher $\alpha_{3}$ ) the more time they are willing to devote to tutor their children, and hence, the higher is the income of the next working generation. 


\subsection{Absence of parental participation}

The withdrawal of parents from education process is a stylized fact of education systems in some advanced and developing countries that has attracted the attention of policymakers. This situation, where utility maximization is attained at $e_{t}(\omega)=0$, occurs under certain conditions. To obtain this, recall that (12) and (13) establish a negative relationship between public education and home tutoring, namely public education substitutes for parental education. For each individual there exists a particular tax rate such that $e_{t}(\omega)=0$, that is, when the marginal utility of working or leisure is larger than the additional utility from an increase in the offspring's human capital due to higher level of parental tutoring. Consider the families which optimally choose $e_{t}(\omega)=0$ and denote this set of families in generation $t$ by $A_{t} \subset$ $G_{t}=[0,1]$. In fact, using (1) and (2), condition (13) holds if:

$$
2-l_{t}(\omega)-e_{t}(\omega)<\frac{\alpha_{4}}{\beta_{1} \alpha_{3}}\left[\beta_{1} e_{t}(\omega)+\beta_{2} e_{g t} \frac{\bar{l}_{t} \bar{h}_{t}^{\eta}}{h_{t}^{v}(\omega)}\right]
$$

Therefore, for each individual $\omega$, we obtain $\omega \in A_{t}$ whenever:

$$
h_{t}^{v}(\omega)<\frac{\left(\alpha_{1}+\alpha_{2}+\alpha_{4}\right) \beta_{2}}{2 \alpha_{3} \beta_{1}} e_{g t} \bar{l}_{t} \bar{h}_{t}^{\eta}
$$

Set $A_{t}$ consists of individuals with sufficiently low level of human capital. This set increases as the efficiency or the level of public education increases, confirming the substitute nature of parental tutoring and public education while it increases as parents in the society care their children very much or as the efficiency of home learning increases, for instance due to technological advancement. Notice also that this set increases with the importance of consumptions or of leisure as individuals prefer spending their time earning income or taking leisure rather than tutoring their children. Consumption parameters $\alpha_{1}$ and $\alpha_{2}$ play no role in establishing set $A_{t}$ when labor is inelastic since they have no effect on labor income (see Viaene and Zilcha, 2003). On the contrary, in our framework such parameters determine individual income through (20) and (2).

\subsection{Insufficient public education provision as source of poverty trap}

Although parental tutoring and public education are substitutes to each other, the long run human capital stock along the equilibrium path is only affected by a provi- 
sion of public education. Specifically, decreasing the level of public education below a certain threshold, conditional on the aggregate human capital level, results in a negative growth rate of the stock of human capital, while a higher provision of public education results, along the equilibrium path, in a positive growth rate. Therefore, our model allows for a poverty trap.

To simplify the analysis, we assume a stationary provision of public education, i.e., $e_{g t}=e_{g}=\tau$ and define $\underline{h}_{t}=\int_{\Omega} \frac{1}{h_{t}^{v}(\omega)} d \mu(\omega)$. A set of plausible restrictions on the parameters are required to establish the following claim: The level of public education in the economy determines the positive or negative accumulation of human capital. Therefore we assume in this section only that the parameters in our economy satisfy the following conditions:

(A1) $\frac{2 \alpha_{3} \beta_{1}}{\alpha_{1}+\alpha_{2}+\alpha_{3}+\alpha_{4}}<1-\xi$, for some $\xi>0$.

(A2) The initial distributions of $l_{0}(\omega)$ and $h_{0}(\omega)$ satisfy $\bar{l}_{0} \geq 1$ and $\bar{h}_{0} \geq 1$, respectively.

(A3) $\eta=1$ and $v=1$.

(A4) $\alpha_{1}+\alpha_{2}+\alpha_{3}+\alpha_{4}=1$.

Proposition 1. Assume that (A1) - (A4) hold. Then:

(a) If e satisfies:

$$
e_{g} \leq\left[\frac{1-2 \beta_{1}}{2 \beta_{2}\left(\alpha_{1}+\alpha_{2}\right)}\right]\left[1+\left[1-2 \alpha_{3} \beta_{1}\right] \frac{1}{2 \beta_{2}} \bar{h}_{t} \underline{h}_{t}\right]^{-1}
$$

for all $t$, then along the equilibrium path, the aggregate human capital decreases, that is, $\bar{h}_{t+1}<\bar{h}_{t}$ for $t=0,1,2, \cdots$

(b) If e satisfies:

$$
e_{g} \geq\left[\frac{1-2 \alpha_{3} \beta_{1}}{2 \alpha_{3} \beta_{2}\left(\alpha_{1}+\alpha_{2}\right)}\right]\left[1+\left[\frac{1}{2 \alpha_{3} \beta_{1}}-1\right] \bar{h}_{t} \underline{h}_{t}\right]^{-1}
$$

for all $t$, then aggregate human capital increases, i.e., $\bar{h}_{t+1}>\bar{h}_{t}$ for all $t$

Proof. See the appendix.

This result emphasizes the crucial role played by the level of public education. To underline this point, consider two countries which differ in the provision of public 
education and in their initial distributions of human capital, given that each economy satisfies (A1)-(A4). If $e_{g}$ is chosen to be low in one country, assuming that condition (26) satisfies, while in the other country it is higher, in the sense that condition (27) holds, then we obtain a poverty trap in the first country while the second has a positive rate of growth. Evidence of countries with declining human capital can be found at the World Bank site.

More importantly, economies with high level of aggregate human capital are less likely to face a poverty trap, namely, the boundary of aggregate human capital below which the poverty trap occurs is lower. ${ }^{8}$ Also, high levels of aggregate human capital guarantee that the aggregate human capital increases. This result differs with one in Viaene and Zilcha (2003) where the assumption of inelastic labor makes the level of society's human capital not playing a role in the condition of poverty trap.

\subsection{Cross-family variation of labor supply}

Explaining the relationship between human capital formation and future income inequality is the main theme of this chapter. In such relationship, labor supply plays an intermediate role since it determines future income through (22) and it is driven by the process of human capital formation. ${ }^{9}$

To see the effect of current family's human capital on future labor supply directly, we do the following. We assume constant returns to scale, i.e., $\eta=1$ and $v=1$ and the existence of no-poverty-trap condition (27). Without loss of generality, we set $\alpha_{1}+\alpha_{2}+\alpha_{3}+\alpha_{4}=1$. After integrating both sides of (20) and conducting some manipulations we obtain:

$$
\bar{l}_{t}=\frac{2\left(\alpha_{1}+\alpha_{2}\right) \beta_{1}}{\left(\alpha_{1}+\alpha_{2}+\alpha_{3}+\alpha_{4}\right) \beta_{1}-\left(\alpha_{1}+\alpha_{2}\right) \beta_{2} \tau_{t} \bar{h}_{t} \underline{h}_{t}}
$$

and at time $t+1$, we substitute (28) back to (20):

$$
l_{t+1}(\omega)=\left(\alpha_{1}+\alpha_{2}\right)\left[2+\frac{2\left(\alpha_{1}+\alpha_{2}\right) \beta_{1} \beta_{2} \tau_{t+1}\left(2 \beta_{1}+\beta_{2} \tau_{t} \bar{l}_{t}\right)}{\theta_{t}(\omega)\left[2 \beta_{1} \frac{h_{t}(\omega)}{\bar{h}_{t}}+\beta_{2} \tau_{t} \bar{l}_{t}\right]\left[\beta_{1}-\left(\alpha_{1}+\alpha_{2}\right) \beta_{2} \tau_{t+1} \bar{h}_{t+1} \underline{h}_{t+1}\right]}\right]
$$

Equation (29) suggests that a higher current aggregate human capital induces

\footnotetext{
${ }^{8} \mathrm{~A}$ higher $\bar{h}_{t}$ means a higher $\bar{h}_{t} \underline{h}_{t}$ which implies a more difficult attainment of poverty trap.

${ }^{9}$ See (1) and one step ahead of (20).
} 
next-period working generation to exert higher labor supply. But individual responses to aggregate human capital differ as explained by the following proposition.

Proposition 2. Consider an economy consisting of individuals with different levels of human capital. Then, the lower the level of human capital of parents at a particular period, the higher the labor supply exerted by the corresponding offspring in the next period.

Proof. The proof is directly taken from (29).

Thus, families with high relative human capital will supply less labor in the future than those with low relative human capital. The difference between the level of a family's human capital and the average level of human capital in the society is crucial as stated in the following corollary.

Corollary. Consider two groups of individuals in a particular time, one with belowaverage human capital and the other with above average human capital. Then in the next period any individual from the former group will supply higher labor than any individual from the latter group.

Parents with above average human capital would transfer their high human capital to their children and as the result, their highly capable children would exert labor less than those with lower human capital. Empirically this is common in countries with weakly-regulated labor market such as in Asia or Latin America.

\section{Capital markets integration}

We rewrite the per capita production function (4) into the aggregate production function:

$$
Q_{t}=F\left(K_{t}, L_{t}^{e}\right)
$$

where $Q_{t}$ is the aggregate output, $K_{t}=\int_{\Omega} s_{t-1}(\omega) d \mu(\omega)$ is the aggregate physical capital and $L_{t}^{e}=\left(1-\tau_{t}\right) L_{t}=\left(1-\tau_{t}\right) \int_{\Omega} l_{t}(\omega) h_{t}(\omega) d \mu(\omega)$ is the aggregate human capital. From this point onward, we assume that the aggregate production function in our economy takes the Cobb-Douglas form:

$$
F\left(K_{t}, L_{t}^{e}\right)=A K_{t}^{\phi}\left(L^{e}\right)_{t}^{1-\phi}
$$


where in equilibrium, the following expressions are therefore obtained: $w_{t}=(1-$ $\phi) A\left(\frac{K_{t}}{L_{t}^{e}}\right)^{\phi}$ and $1+r_{t}=\phi A\left(\frac{K_{t}}{L_{t}^{e}}\right)^{(\phi-1)}$.

Substituting (10) and (11) to (6) while making use of (7), the economy's aggregate income at date $t$ :

$$
\int_{\Omega} y_{t}(\omega) d \mu(\omega)=\left(1+\frac{\alpha_{1}}{\alpha_{2}}\right) K_{t+1}
$$

We know that (2) gives income at date $t$ and using this we can write aggregate income as a proportion of aggregate output as:

$$
\int_{\Omega} y_{t}(\omega) d \mu(\omega)=(1-\phi) Q_{t}
$$

\subsection{Comparing two economies under autarky}

Assume that the world consists of two economies: domestic and foreign. Assume also that domestic is initially endowed with more physical capital and the endowments of labor supply and of human capital in the two countries are similar. Foreign variables are marked with $\left(^{*}\right)$. We define the growth factor of aggregate effective human capital as:

$$
\gamma_{t}=\frac{L_{t+1}}{L_{t}}=\frac{\int_{\Omega} l_{t+1}(\omega) h_{t+1}(\omega) d \mu(\omega)}{\int_{\Omega} l_{t}(\omega) h_{t}(\omega) d \mu(\omega)} .
$$

Therefore we have $\gamma_{t}=\gamma_{t}^{*}$ and hence $L_{t}=L_{t}^{*}$ for all $t$. From (32) and (33) we have:

$$
\frac{K_{t+1}}{K_{t}}=\left[\frac{(1-\phi) A \alpha_{2}}{\alpha_{1}+\alpha_{2}}\right]\left[\frac{L_{t}^{e}}{K_{t}}\right]^{1-\phi}
$$

Dividing by (34) results in:

$$
\frac{K_{t+1}}{L_{t+1}}=\left[\frac{(1-\phi) A \alpha_{2}\left(1-\tau_{t}\right)^{1-\phi}}{\gamma_{t}\left(\alpha_{1}+\alpha_{2}\right)}\right]\left[\frac{K_{t}}{L_{t}}\right]^{\phi}
$$

This is the dynamic path of capital-labor ratio of each economy in Autarky. Clearly, if $\frac{K_{0}}{L_{0}}>\frac{K_{0}^{*}}{L_{0}^{*}}$, then $\frac{K_{t}}{L_{t}}>\frac{K_{t}^{*}}{L_{t}^{*}}$ for all $t$, which implies $Q_{t}>Q_{t}^{*}$ and $K_{t}>K_{t}^{*}$ for $t$. The following proposition summarizes this result.

Proposition 3. Consider the domestic and foreign economies in autarky under the assumptions: $l_{0}(\omega)=l_{0}^{*}(\omega), h_{0}(\omega)=h_{0}^{*}(\omega)$ and $K_{0}>K_{0}^{*}$. Then $Q_{t}>Q_{t}^{*}$ and $K_{t}>K_{t}^{*}$ for all dates. 
Proof. See above.

Therefore, the economy which starts from higher capital stock, while other parameters are equal, attains higher output in all subsequent periods.

\subsection{Equilibrium under capital markets integration}

Consider that at time $t=0$ the domestic and foreign economies integrated to form a single commodity market and a single capital market while labor remains internationally immobile. The two economies are assumed to be identical in all aspects including public education expenditure, $\tau_{t}=\tau_{t}^{*}$ except for the distribution of human capital. After the integration of capital markets, physical capital will flow from the low return to the high return economy until rates of return are equalized. This type of international capital movement involves a change in location but not a change in ownership. Post-integration variables are marked with $(\sim)$.

We define $\tilde{K}_{t}$ as capital stock used in production in the domestic country and $\tilde{T}_{t}$ as capital stock, located at home and abroad, owned by domestic residents. We rewrite (10) after integration as follows:

$$
\tilde{T}_{t+1}=\int_{\Omega} \tilde{s}_{t}(\omega) d \mu(\omega)
$$

Since positive $\tilde{T}_{t}-\tilde{K}_{t}$ corresponds to a net outflow of domestic capital abroad, the following identity must hold:

$$
\tilde{T}_{t}+\tilde{T}_{t}^{*}=\tilde{K}_{t}+\tilde{K}_{t}^{*}
$$

Positive $\tilde{K}_{t}-\tilde{T}_{t}$ therefore corresponds also to net inflow of capital in foreign country. Substituting (37) into (38) leads to:

$$
\int_{\Omega}\left[\tilde{s}_{t}(\omega)+\tilde{s}_{t}^{*}(\omega)\right] d \mu(\omega)=\tilde{K}_{t+1}+\tilde{K}_{t+1}^{*}
$$

which is an analog of (10) for the integrated economy. Similar with autarky equilibrium in (32) and (33), we obtain:

$$
\begin{gathered}
\int_{\Omega}\left[\tilde{y}_{t}(\omega)+\tilde{y}_{t}^{*}(\omega)\right] d \mu(\omega)=\left(1+\frac{\alpha_{1}}{\alpha_{2}}\right)\left[\tilde{K}_{t+1}+\tilde{K}_{t+1}^{*}\right] \\
\int_{\Omega}\left[\tilde{y}_{t}(\omega)+\tilde{y}_{t}^{*}(\omega)\right] d \mu(\omega)=(1-\phi)\left[\tilde{Q}_{t+1}+\tilde{Q}_{t+1}^{*}\right]
\end{gathered}
$$


Proposition 4. Total output of the integrated economy after capital market integration is higher than the sum of outputs of the autarkic economies at all dates.

Proof. See the appendix.

Equality of returns to capital has implication for capital labor ratio as follows:

$$
\frac{\tilde{K}_{t}}{\tilde{L}_{t}^{e}}=\frac{\tilde{K}_{t}^{*}}{\tilde{L}_{t}^{e *}}=\frac{\tilde{K}_{t}+\tilde{K}_{t}^{*}}{\tilde{L}_{t}^{e}+\tilde{L}_{t}^{e *}}, \quad t=0,1,2, \cdots .
$$

And from the assumptions of identical and linear homogenous production functions we obtain:

$$
\frac{\tilde{Q}_{t}}{\tilde{K}_{t}}=\frac{\tilde{Q}_{t}^{*}}{\tilde{K}_{t}^{*}}=\frac{\tilde{Q}_{t}+\tilde{Q}_{t}^{*}}{\tilde{K}_{t}+\tilde{K}_{t}^{*}}, \quad t=0,1,2, \cdots .
$$

Combining these two expressions:

$$
\frac{\tilde{Q}_{t}}{\tilde{Q}_{t}+\tilde{Q}_{t}^{*}}=\frac{\tilde{K}_{t}}{\tilde{K}_{t}+\tilde{K}_{t}^{*}}=\frac{\tilde{L}_{t}^{e}}{\tilde{L}_{t}^{e}+\tilde{L}_{t}^{e *}}
$$

Therefore, following capital markets integration, each country's share of output and share of physical capital stock in the integrated economy is equal to its share in the stock of effective human capital. This is basically the equal-share relationship discussed in Chapter 2.

More importantly, equality of returns implies equality of capital labor ratio and hence equality of equilibrium real wage rates as presented below:

$$
\tilde{w}_{t}=(1-\phi) A\left(\frac{\tilde{K}_{t}}{\tilde{L}_{t}^{e}}\right)^{\phi}=(1-\phi) A\left(\frac{\tilde{K}_{t}^{*}}{\tilde{L}_{t}^{* e}}\right)^{\phi}=\tilde{w}_{t}^{*}
$$

\section{Income inequality}

Distributional equity is a paramount issue both in theory and in practice. Such issue is increasingly pressing economists and policy makers following the globalization with the integration of capital markets as one of its consequences. There is a conventional wisdom that the relationship between income inequality and economic growth depends on the conditions in each country and education policies implemented by each government. To simplify our analysis, we focus on the intragenerational income distributions for the domestic and foreign economies. We will show that a nation's distribution of income is not affected by capital markets integration. 
Consider $X$ and $W$ as two random variables with values in a bounded interval in $(-\infty, \infty)$ and let $m_{x}$ and $m_{w}$ represent their respective means. Let $F_{x}$ and $F_{w}$ be the cumulative distribution functions of $\hat{X}$ and $\hat{W}$, respectively where $\hat{X}=\frac{X}{m_{x}}$ and $\hat{W}=\frac{W}{m_{w}}$. Let $[a, b]$ be the smallest interval enclosing the supports of $\hat{X}$ and $\hat{W}$.

Definition. $F_{x}$ is more equal than $F_{w}$ if, for all $t \in[a, b], \int_{a}^{t}\left[F_{x}(s)-F_{w}(s)\right] d s \leq 0$ for all $t, a \leq t \leq b$ and $F_{x}(s) \neq F_{w}(s)$ for some $s$.

This is identical with the requirement that the Lorentz curve corresponding to $W$ is everywhere below that of $X$ (Atkinson, 1970). We say that $X$ is more equal than $W$ if $F_{x}$ is more equal than $F_{w}$. From this point, the relation $X$ is more equal than $W$ is indicated as $X \gg W$. We state that $X$ is equivalent to $W$, denoted with $X \sim W$, if $X \gg W$ and $X \ll W$.

\subsection{Invariance in inequality}

Without loss of generality, let us assume again that $\alpha_{1}+\alpha_{2}+\alpha_{3}+\alpha_{4}=1, \tau_{t}=\tau_{t+1}=\tau$ and there is constant returns to scale in the human capital production. We will employ some results derived in previous sections to express the individual income at time $t+1, y_{t+1}$, in terms of initial human capital $h_{0}(\omega)$ and some (wage-invariant) aggregate variables. First, rewriting (2) using (20) we obtain:

$$
y_{t}(\omega)=\left(\alpha_{1}+\alpha_{2}\right) \frac{\beta_{2}}{\beta_{1}} w_{t}(1-\tau) \tau \tilde{l}_{t} \tilde{h}_{t}+2\left(\alpha_{1}+\alpha_{2}\right) w_{t}\left(1-\tau_{t}\right) h_{t}(\omega) .
$$

Assuming parental participation, $e_{t}(\omega)>0$, using (23) and after some manipulations, the next-period individual income can be expressed using (45) as follows:

$$
y_{t+1}(\omega)=\left(\alpha_{1}+\alpha_{2}\right) w_{t+1}(1-\tau)\left[\frac{\beta_{2}}{\beta_{1}} \tau \tilde{l}_{t+1} \tilde{h}_{t+1}+2 \alpha_{3} \beta_{2} \tau \tilde{l}_{t} \tilde{h}_{t} \theta_{t}(\omega)+4 \alpha_{3} \beta_{1} \theta_{t}(\omega) h_{t}(\omega)\right] \text {. }
$$

Observe that the evolution process of human capital of a family can be written as follows:

$$
h_{t}(\omega)=\left[\Psi_{t}(\omega)+\Delta_{t}(\omega) h_{0}(\omega)\right]
$$

where

$$
\Psi_{t}(\omega)=\sum_{k=0}^{t-1} 2^{k} \alpha_{3}^{k+1} \beta_{1}^{k} \beta_{2} \tau \tilde{l}_{t-1-k} \tilde{h}_{t-1-k} \phi_{r=0}^{k} \theta_{t-1-r}(\omega)
$$


and

$$
\Delta_{t}(\omega)=\left[2 \alpha_{3} \beta_{1}\right]^{t} \phi_{k=0}^{t-1} \theta_{k}(\omega) .
$$

With such representation of $h_{t}(\omega)$, we shall examine the impact of capital markets integration on the intragenerational income inequality. We can rewrite (46) as follows:

$$
y_{t+1}(\omega)=\left(\alpha_{1}+\alpha_{2}\right) w_{t+1}(1-\tau)\left[\frac{\beta_{2}}{\beta_{1}} \tau \tilde{l}_{t+1} \tilde{h}_{t+1}+2 \alpha_{3} \beta_{2} \tau \tilde{l}_{t} \tilde{h}_{t} \theta_{t}(\omega)+4 \alpha_{3} \beta_{1} \theta_{t}(\omega)\left[\Psi_{t}(\omega)+\Delta_{t}(\omega) h_{0}(\omega)\right]\right]
$$

For families without parental participation, $e_{t}(\omega)=0$, we rewrite $(2)$ using $(21)$ and obtain:

$$
y_{t}(\omega)=\frac{2\left(\alpha_{1}+\alpha_{2}\right)}{\alpha_{1}+\alpha_{2}+\alpha_{4}} w_{t}(1-\tau) h_{t}(\omega)
$$

The next-period individual income can be expressed using (49) and (24) as follows:

$$
y_{t+1}(\omega)=\frac{2\left(\alpha_{1}+\alpha_{2}\right) \beta_{2}}{\alpha_{1}+\alpha_{2}+\alpha_{4}} w_{t+1}(1-\tau) \tau \theta_{t}(\omega) \bar{l}_{t} \bar{h}_{t}
$$

Now, we prove the following result.

Proposition 5. Given the initial distributions in both countries at date 0, assume that $K_{0}>K_{0}^{*}$ Capital mobility resulting from integration of capital markets do not alter the intragenerational income inequality in each economy observed under autarky.

Proof. See the appendix.

Inequality in our economy results from one source only, that is, unequal human capital distribution. In the domestic economy, capital markets integration results in lower wage rates in all subsequent periods. As a result, income differences between families resulting from labor earnings due to human capital inequality (and hence also due to variation in labor supply) will be reduced. However, by the proof of Proposition 5, it does not affect inequality in income distribution, since all incomes are varied in the same proportion. Also, under certain condition, Proposition 5 implies an invariant relationship of income inequality between domestic and foreign.

Corollary. Assume that initial labor supplies and human capital distributions satisfy $l_{0}(\omega)=l_{0}^{*}(\omega)$ and $h_{0}(\omega)=h_{0}^{*}(\omega)$ while $K_{0}>K_{0}^{*}$. Then, before and after integration 
inequality in the income distributions is the same for all periods, both in the autarky equilibrium and under capital markets integration, namely, $y_{t} \sim y_{t}^{*} \sim \tilde{y}_{t} \sim \tilde{y}_{t}^{*}$.

It is widely recognized that capital markets integration has a significant impact on wages, output and interest rates of the two economies. However, it is obvious from equations (46)-(50), that in this framework, such variations in the equilibrium factor prices do not affect our results concerning income inequality since labor incomes change in the same proportion. Hence capital markets integration plays no role in explaining income inequality in this model.

Introducing intergenerational transfer of physical capital (bequest) in the economy will modify some of the results because movement in factor prices affects individuals differently. ${ }^{10}$ However, there is an ongoing debate as to the importance of such transfer between generations. The magnitude of bequest-motivated saving remains unclear. More importantly, the empirical evidence seems to suggest that among families, bequests are far from universal. Laitner (1997) provides a survey on this issue.

\subsection{Initial endowments and inequality}

The Corollary after Proposition 5 explains the intergenerational income inequality in a specific situation, that is, when the initial endowments of the domestic and foreign economies are identical. We now consider a situation where one economy has higher level of human capital but we retain the assumption that the initial inequality of human capital distributions is the same.

Proposition 6. Consider two economies which differ only in their initial human capital distribution, $h_{0}(\omega)$ and $h_{0}^{*}(\omega)$. Assume that $h_{0}^{*}(\omega)>h_{0}(\omega)$ for all $\omega$, but the initial distributions of both labor supply and human capital have the same level of inequality. Then, the equilibrium from $h_{0}^{*}(\omega)$ will have lower income inequality then that from $h_{0}(\omega)$ at all dates.

Proof. See the appendix.

Therefore, the initial inequality of human capital matters: an economy that begins with lower levels of capital, but perhaps not less equal, has a better chance

\footnotetext{
${ }^{10}$ See, for example, Viaene and Zilcha (2002).
} 
to maintain more inequality in its future distribution of income.

\subsection{Public education and inequality}

Suppose that the government does not contribute to human capital formation, that is, $\tau_{t}=0$. In this situation:

$$
y_{t+1}(\omega)=w_{t+1} l_{t+1}(\omega) h_{t+1}(\omega) .
$$

From (25), we know that set $A_{t}$ is empty and from (19) we obtain:

$$
e_{t}(\omega)=e^{*}(\omega)=\frac{2 \alpha_{3}}{\alpha_{1}+\alpha_{2}+\alpha_{3}+\alpha_{4}} \quad \text { for all } \omega
$$

which is a constant. It is clear that when public education is unavailable, the initial distribution of human capital is the only source of income inequality. In particular, we have:

$$
y_{t+1}(\omega)=\frac{2\left(\alpha_{1}+\alpha_{2}\right) \beta_{1}}{\alpha_{1}+\alpha_{2}+\alpha_{3}+\alpha_{4}}\left[w_{t+1} e^{*}(\omega) h_{t}^{v}(\omega)\right] \theta_{t}(\omega)
$$

The following proposition summarizes the above examination.

Proposition 7. Without public education provision, income inequality $(i)$ declines over time under decreasing returns (i.e., if $v<1$ ), (ii) increases over time under increasing returns (i.e., if $v>1$ ) and (iii) remains constant over time under constant returns (i.e., if $v=1$ ).

Proof. The proof is directly taken from (53).

In equilibrium, the economy generates an intragenerational income distribution with inequality endogenously determined by the externality of parental tutoring. On one hand, when $v<1$, inequality declines even in the absence of public education. On the other hand, when $v>1$, severe inequality in the form of "poverty trap" may arise (i.e., $h_{t}(\omega)$ goes to zero) for some families whose initial human capital is below a certain threshold level, that is when:

$$
h_{0}(\omega)<\left[\frac{\alpha_{1}+\alpha_{2}+\alpha_{3}+\alpha_{4}}{2 \beta_{1} \alpha_{3} \theta_{0}(\omega)}\right]^{\frac{1}{v-1}}
$$

The latter situation divides the population into two segments: families whose human capital below this threshold face a permanent decrease in human capital while those 
with human capital above this critical level undergo a permanent improvement. The empirical evidence of such situation is found in some developing countries such as China, India or Indonesia, where increasing returns in parents' human capital and very low public education expenditure have been observed. ${ }^{11}$

Starting now we assume the existence of public education provision whose level is determined exogenously. Following (3), the level at date $t$ is $e_{g t}$ and it is financed by taxing income at a fixed rate $\tau_{t}\left(=e_{g t}\right)$. To simplify the analysis in the sequel we assume that $v \leq 1, \eta \leq 1$ and $v \leq \eta$. The relation between public education and income inequality is summarized in the following proposition.

Proposition 8. Let $h_{0}(\omega)$ be any initial human capital distribution. (i) If the tax rate that finances public education is the same for all dates, then income inequality at date $t+1$ is smaller than that in date $t$. (ii) Increasing the tax rate (hence, the public education provision) results in a more equal intragenerational distribution in all subsequent period.

Proof. See the appendix.

This result underlines the role of public education to weaken the effect of family characteristics. This is because public education is provided to all children of the same generation equally independent of their parents' human capital. Such dampening feature makes human capital (and hence income) more equal over time. In other words, when human capital formation has a constant or decreasing returns to scale, public education forces the current economic disparities to decrease over time.

Moreover, if one compares two economies whose all attributes are similar except for the level of public education, the country which invests more will face a lower inequality along the equilibrium path and for all subsequent periods.

\subsection{Education technology and inequality}

We now analyze cross country variation in technology of human capital formation (1) and its impact on income inequality. Introducing a new technology brings an improvement to the human capital production. Such an improvement can be conducted by increasing efficiency of education process, for instance through the introduction

\footnotetext{
${ }^{11}$ For example, see Knight and Shi (1996).
} 
of more advanced facilities (computer, internet, e-library, etc.), the reduction of class size, the increase of teaching hours and the improvement of school management. This equals to increasing the parameters $\beta_{1}$ or $\beta_{2}$ or both. Another improvement can be by enhancing the effectiveness of 'school teachers' or 'tutoring parents' through for example, better training for teachers and providing information to parents on how to educate their children. Such improvement is equivalent with rising the parameters $v$ or $\eta$ or both. Here we make assumptions that $v \leq 1, \eta \leq 1$ and $\eta \geq \frac{1}{2} v$, which can be loosened in most cases. $^{12}$

A technological improvement of the production of human capital in a particular economy may result in a more efficient parental tutoring or more efficient public education, or both. We say that the provision of public education becomes more efficient if either $\frac{\beta_{2}}{\beta_{1}}$ is higher while neither $\beta_{1}$ nor $\beta_{2}$ declines, or $\eta$ increases, or both. We claim that the provision of private education is more efficient if $\frac{\beta_{1}}{\beta_{2}}$ is larger without lowering neither neither $\beta_{1}$ nor $\beta_{2}$, or $v$ is higher, or both. The educational technological is called neutral in the case where both parameters $\beta_{1}$ and $\beta_{2}$ rises while the ratio $\frac{\beta_{1}}{\beta_{2}}$ continues unchanged.

Proposition 9. Consider improvements in the production process of human capital, then: (a) If the provision of public education becomes more efficient, the inequality in intragenerational distribution of income decreases in all periods; (b) If the provision of private education becomes more efficient then inequality rises in all periods; (c) If the technological improvement is neutral inequality continues unchanged at period 1 but declines for all periods afterwards.

Proof. See the appendix.

The result shows the opposite effects on inequality between a technological improvement that occurs in the public education and the one that exists in home education. The inequality in human capital distribution declines following a more efficient public education because all children are taught by instructors whose level of human capital is the same: the above-average children have a lower return to public education than below-average children. Conversely, a more efficient private

\footnotetext{
${ }^{12}$ It is hardly possible that the human capital of teachers or parents can be fully 'transferred' to the children.
} 
education increases inequality. The reason is that when the family-specific education becomes more efficient, the family attributes are intensified. An example of this is the experience of "digital-divide" in a number of developing countries, where above-average families reap more benefit from information technology as learning tools than below-average families.

\section{Numerical simulation}

In this section we will compute the equilibrium paths by simulation for an example. Then the properties concerning inequality, growth, wage rental ratio, parental tutoring and family labor supply are compared.

The previous propositions mark education systems as the main driving force of income inequality in equilibrium. Although the human capital production processes vary substantially across countries, it is interesting to gain insight whether such discrepancy is significant in explaining observed differences in income inequality. The objective of this simulation is to quantify the response of income inequality to changes in the parameters of education technology. We will establish a dynamic computable general equilibrium model with heterogenous agents based on the theory. This method tracks the time path follows by each family and investigates how they respond to different education systems. The simulation generates some aggregation variables such as the Gini coefficient, the growth rate of output and the wage rental ratio.

Table 1: Data of The Netherlands (1975-2000) taken as the baseline economy

\begin{tabular}{lc}
\hline \hline Variable & Value \\
\hline Gini coefficient, disposable income (2000) & 0.325 \\
Public education expenditure (\% of GDP, 1999 & 5.1 \\
Output level $\left(10^{9}\right.$ Euro, 2000) & 401.089 \\
Growth rate, real GDP per capita (\%, 1975-2000) & 56.94 \\
Capital coefficient (Euro, 2000) & 4.6 \\
Employment $\left(10^{5}, 2000\right)$ & 69.17 \\
\hline
\end{tabular}

Source: Central Bureau of Statistics of The Netherlands.

The deterministic equilibrium, that is, when random abilities are set to their mean, is calibrated on statistics from the Netherlands over the period 1975-2000. Data for the key variables are summarized in Table 1. 
Table 2: Parameters of the baseline economy

\begin{tabular}{llllll}
\hline \hline$\phi$ & $\mathrm{A}$ & $\beta_{1}$ & $\beta_{2}$ & $v$ & $\eta$ \\
0.3 & 4.599 & 3.440 & 6.091 & 1 & 1 \\
\hline$\alpha_{1}$ & $\alpha_{2}$ & $\alpha_{3}$ & $\alpha_{4}$ & $\tau_{-1}$ & $\bar{l}_{-1} \bar{h}_{-1}$ \\
2.537 & 2.537 & 1.3 & 1.6 & 0.051 & 89.61 \\
\hline
\end{tabular}

To facilitate the analysis, the following assumptions have been made to compute the calibrated parameters which are presented in Table 2:

Human capital. The stock of effective human capital at $t=-1$ is approximated in two steps. Total employment is first divided in 7 scholastic achievements ranging from primary school to university degree. Using the wage of each educational type relative to that of a worker with a primary school certificate as wight, the weighted sum over educational types provides our proxy for the stock of effective human capital. While the actual employment in 2000 is 69.17 hundred thousand, our proxy $\bar{l}_{t} \bar{h}_{t}$ is 89.61 hundred thousand primary school equivalent workers.

Families. We consider 13 heterogeneous families with a human capital at $t=-1$ taking values $2.1,2.4,2.6,3.0,3.6,4.4,5.5,7.3,8.9,11.1,12.3,12.7$ and 13.8. Each family has an initial $\omega=A, B, \ldots L$ and $M$. These imaginary families are chosen with two criteria in mind. First, the sum of individual endowments of human capital is 89.61. Second, they have the Gini coefficient equal to 0.325, the observed Gini coefficient in 2000. The following formula for the Gini coefficient is used:

$$
g_{t}=\frac{1}{2 n(n-1) \bar{y}_{t}} \sum_{i=1}^{n} \sum_{j=1}^{n}\left|y_{i}-y_{j}\right|
$$

where $n=13$ represents the number of families, $\bar{y}_{t}$ is average income, $y_{i}$ and $y_{j}$ are individual incomes.

Preferences. We select $\alpha_{1}$ and $\alpha_{2}$ to obtain net savinigs. Parameter $\alpha_{3}$ is picked such that the poorest familiy $A$ does not participate to the education process, namely $e_{-1}=0$. Also, $\alpha_{4}$ is chosen based on the available empirical evidence concerning leisure.

Human capital formation. Parameters $\beta_{1}$ and $\beta_{2}$ are created to obtain $e_{-1}=0$ and to calibrate the observed growth rate of the economy.

We construct two base settings, one with random inborn abilities and the other with deterministic abilities. After calibrating the parameters, the equilibrium paths of all the families are generated in the following stages. (1) For the first scenario, a 
random number generator draws an innate ability $\theta_{t}$ at each date $t(t=-1,0, \cdots)$ from a normal distribution with mean 1 and standard deviation 0.1. For the second base setting, $\theta_{t}$ is simply set to 1 . (2) Assuming fixed education expenditure, the human capital of any individual at date $t$ is given by (23) and (24). (3) The labor supply is given by (20) and (21). (4) The level of aggregate effective human capital, $L_{t}^{e}$ is computed and the level of aggregate capital stock, $K_{t}$, is equated to past savings. (5) After constructing $q_{t}, w_{t}$ and $\left(1+r_{t}\right)$, each individual income $y(\omega)$ is computed and the Gini coefficient is derived. (6) Given the wage rate $w_{t}$, the interest factor $\left(1+r_{t}\right)$ and income of each family $y_{t}(\omega)$, each individual can compute $e_{t}(\omega)$, $l_{t}(\omega), c_{1 t}(\omega), c_{2 t}(\omega)$ and $s_{t}(\omega)$.

Table 3: Simulation results on the equilibrium paths

\begin{tabular}{lcc}
\hline \hline Variable & $\begin{array}{c}\text { No random inborn ability } \\
\text { (deterministic solution) }\end{array}$ & $\begin{array}{c}\text { With random inborn ability } \\
\text { (stochastic solution) }\end{array}$ \\
\hline Gini coefficient & 0.325 & 0.323 \\
& 0.252 & 0.265 \\
& 0.140 & 0.164 \\
Growth rate of output & 0.077 & 0.124 \\
& $58.87 \%$ & $58.39 \%$ \\
& $24.51 \%$ & $24.04 \%$ \\
& $19.01 \%$ & $19.06 \%$ \\
Wage-rental ratio & $19.01 \%$ & $19.42 \%$ \\
$\left(\frac{w}{1+r_{t}}\right)$ & 2.381 & 2.391 \\
& 3.411 & 3.427 \\
& 3.592 & 3.590 \\
Parental tutoring & 3.592 & 3.575 \\
(poorest family, $e(A))$ & 0.033 & 0.047 \\
& 0.112 & 0.116 \\
& 0.184 & 0.162 \\
& 0.205 & 0.171 \\
\hline Family labor supply & 1.501 & 1.489 \\
(poorest family, $l(A))$ & 1.438 & 1.435 \\
& 1.381 & 1.398 \\
& 1.365 & 1.391 \\
\hline
\end{tabular}

Notes: Column (1) reports the equilibrium achieved assuming the calibrated parameters of Table 2 and random inborn ability fixed to unity. Column (2) assumes random ability. For each variable, the first entry is the solution at date $t=0$, the second, third and fourth rows present the averages over the first 10 periods, the second 10 and the third 10, respectively.

Table 3 presents the solutions of our calibrated economy with and without random abilities. Using the parameters in Table 2 and the initial conditions at $t=-1$, the economy starts at $t=0$ and an equilibrium path is computed for 200 periods. 
Since patterns appear within 30 periods, we ignore the last 170 periods and show the results for $t=0$ and the averages over the first 10 periods, the second 10 and the third 10. The results without random abilities in column (1) is the closest to the actual data of Table 1 while those with random abilities in column (2) approximate the solution.

Because of public education, intragenerational income inequality declines over time as stated in Proposition 8 and confirmed by simulation result in Table 3 . Moreover, though families start with different endowments at date $t=-1$, such discrepancy is dampened within 30 periods. As expected, in the scenario with random abilities the speed of family convergence is reduced.

Proposition 1 suggests the possibility of poverty trap for economies with low education expenditure. Although Dutch public education spending (5.1\%) is low by international standard, Dutch economy always experience non-negative growth. It is still the case even if there is no public education provision $\left(e_{g}=\tau=0\right)$. The reason is that given our calibrated parameters, there is no possibility of poverty trap. Direct computations of the right hand side of (26) for the periods under investigation always give a negative value. Hence set $A_{t}$ in (25) would be empty since all families increase their participation in home education over time.

Table 4: Response elasticities on the equilibrium paths

\begin{tabular}{lccccc}
\hline \hline Variable & $\tau$ & $\beta_{1}$ & $\beta_{2}$ & $v$ & $\eta$ \\
\hline Gini coefficient & -0.7881 & 0.3644 & -0.3844 & 4.2828 & -0.3565 \\
& -1.5657 & 0.7966 & -0.7906 & 6.3404 & -1.4756 \\
\hline Growth rate of output & 0.7480 & 5.1699 & 0.3628 & 8.7955 & 0.4614 \\
& 0.8142 & 5.8894 & 0.3851 & 9.8938 & 0.9803 \\
\hline Wage-rental ratio & -0.1865 & -1.1468 & -0.0926 & -2.6800 & -0.1091 \\
$\left(\frac{w_{t}}{1+r_{t}}\right)$ & -0.1865 & -1.2037 & -0.0870 & -2.7812 & -0.2280 \\
\hline Parental tutoring & -3.9123 & 1.7481 & -1.8827 & -0.7671 & -2.6851 \\
(poorest family, $e(A))$ & -1.4704 & 0.6441 & -0.7018 & -0.2176 & -2.3843 \\
\hline Family labor supply & 0.1808 & -0.0811 & 0.0871 & 0.2500 & -0.1678 \\
(poorest family, $l(A))$ & 0.1288 & -0.0565 & 0.0615 & 0.1745 & -0.1763 \\
\hline
\end{tabular}

Notes: For each variable, the first row reports the average elasticity over the first 10 periods and the second row, the average elasticity over the second 10 periods.

Next we take the setting of Dutch economy with random inborn ability as the hypothetical economy and perturb the parameters $\beta_{1}, \beta_{2}, v, \eta$ and $\tau$ one by one. 
The small changes involve an increase or a decrease of the parameters by $10 \%$. Table 4 presents the response elasticities along the equilibrium path of the aggregate variables Gini coefficient, the growth rate output and the wage rental ratio. The table also shows the parental tutoring and the labor supply of the poorest family at $t=-1$.

Column 1 of Table 4 shows the response with respect to $\tau_{t}$ and therefore compare economies with different exogenous levels of educational expenditures. This column confirms the results of Proposition 8 that an economy with 10 percent more educational expenditure than in the Netherlands will experience a 8 percent drop in Gini coefficient during the first 10 periods and a 16 percent drop during the second 10 periods. This trend to equality is coupled with a considerable increase of output growth: a 7 percent rise during the first 10 periods and a 8 percent rise during the second 10 periods. As parental tutoring decreases, the effects on wage-rental ratio and labor supply are moderate as evidenced by the small elasticities. Column (2) to (5) report the response elasticities with respect to education parameters. These elasticities describe economies with different characteristics of parental tutoring (i.e., different $\beta_{1}$ and $v$ ) and of public education (i.e., different $\beta_{2}$ and $\eta$ ). Elasticities in columns (2) and (3) are calculated for an increase in $\beta_{1}$ and in $\beta_{2}$ while those in columns (4) and (5) are computed for a decrease in $v$ and in $\eta$ to reflect plausible situations. It is clear that when $\beta_{1}$ or $v$ increases, more inequality in income distribution exists and it is coupled with higher economic growth. On the other hand, when $\beta_{2}$ or $\eta$ increases, less inequality in income distribution is observed, also together with higher growth. This simulation result confirms the theoretical findings of Proposition 9. Moreover, they provide insights in explaining the ambiguous relationships between income inequality and economic growth.

\section{Concluding remarks}

We have studied the consequences of various processes of human capital formation on income inequality in an overlapping generations economy with heterogenous agents. The heterogeneity in our model emanates from the initial distribution of human capital across individuals and from the random inborn abilities. Our results offer some insights concerning a relation between income inequality and various features 
of the process of human capital formation, which includes: (a) the international environment, such as physical capital mobility (b) the initial conditions of stock of human capital (c) the level and externality of public education (d) the efficiency originated from education technology.

This chapter also shows the invariance property of inequality. This feature suggests that although wage rates are equalized after capital markets integration, inequality remains unchanged since all individual incomes are affected by the same proportion. We also derive a condition that allows for poverty trap and for positive growth of human capital to occur, both of which depending on the current level of human capital in the economy.

Our framework makes a specific assumption regarding the functional form of the human capital production which may raise some robustness issues. First, the inclusion of parental role in the human capital formation process is in fact justified due to its empirical relevance in a number of countries. Second, labor is assumed to have no specialization. They are capable to teach and to produce consumption goods with the same quality (perfect substitute). Third, there is no tax on the returns to savings, but incorporating such tax will not change the results concerning income inequality.

\section{Appendix: proofs}

Proof of Proposition 1: To proof part (a), consider the inequality (25) which defines the set $A_{t}\left(A_{t} \neq 0\right)$. Using (23), (24), (A3) and (A4) we derive:

$$
\bar{h}_{t+1}=2 \alpha_{3} \beta_{1} \int_{\sim A_{t}} h_{t}(\omega) d \mu(\omega)+\left(1-\mu\left(A_{t}\right)\right) \alpha_{3} \beta_{2} e_{g} \bar{l}_{t} \bar{h}_{t}+\mu\left(A_{t}\right) \beta_{2} e_{g} \bar{l}_{t} \bar{h}_{t}
$$

Therefore,

$$
\bar{h}_{t+1}<2 \alpha_{3} \beta_{1} \int h_{t}(\omega) d \mu(\omega)+\alpha_{3} \beta_{2} e_{g} \bar{l}_{t} \bar{h}_{t}+\mu(A)\left(\alpha_{1}+\alpha_{2}+\alpha_{4}\right) \beta_{2} e_{g} \bar{l}_{t} \bar{h}_{t}
$$

To have $\bar{h}_{t+1}<\bar{h}_{t}$, we need to show that:

$$
\alpha_{3}\left[2 \beta_{1}+\beta_{2} e_{g} \bar{l}_{t}\left(1+\mu\left(A_{t}\right) \frac{\alpha_{1}+\alpha_{2}+\alpha_{4}}{\alpha_{3}}\right)\right] \leq 1
$$

Thus, if we replace $\mu\left(A_{t}\right)$ by 1 , then from (57) we obtain:

$$
e_{g} \leq\left[1-2 \alpha_{3} \beta_{1}\right] \beta_{2}^{-1} \bar{l}_{t}^{-1}
$$


Integrating both sides of (20) we have:

$$
\bar{l}_{t}^{-1}=\frac{1}{2\left(\alpha_{1}+\alpha_{2}\right)}-\frac{\beta_{2}}{2 \beta_{1}} e_{g} \bar{h}_{t} \underline{h}_{t}
$$

and after substituting (59) into (58) we obtain the inequality (26). (Q.E.D.)

To proof part (b) consider (56) above. It is clear that:

$\bar{h}_{t+1}=2 \alpha_{3} \beta_{1} \bar{h}_{t}-2 \alpha_{3} \beta_{1} \int_{A_{t}} h_{t}(\omega) d \mu(\omega)+\alpha_{3} \beta_{2} e_{g} \bar{l}_{t} \bar{h}_{t}+\left(\alpha_{1}+\alpha_{2}+\alpha_{4}\right) \mu\left(A_{t}\right) \beta_{2} e_{g} \bar{l}_{t} \bar{h}_{t}$.

However, using inequality (25), we obtain that $\int_{A_{t}} h_{t}(\omega) d \mu(\omega)<\mu\left(A_{t}\right) \frac{\left(\alpha_{1}+\alpha_{2}+\alpha_{4}\right) \beta_{2}}{2 \alpha_{3} \beta_{1}} e_{g} \bar{l}_{t} \bar{h}_{t}$ and therefore:

$$
\bar{h}_{t+1}>2 \alpha_{3} \beta_{1} \bar{h}_{t}+\alpha_{3} \beta_{2} e_{g} \bar{l}_{t} \bar{h}_{t}
$$

Thus $\bar{h}_{t+1}>\bar{h}_{t}$ holds whenever $2 \alpha_{3} \beta_{1}+\alpha_{3} \beta_{2} e_{g} \bar{l}_{t} \geq 1$ or:

$$
e_{g} \geq \frac{1-2 \alpha_{3} \beta_{1}}{\alpha_{3} \beta_{2}} \bar{l}_{t}^{-1}
$$

Substituting (59) into (60), we obtain the inequality (27). (Q.E.D.)

Proof of Proposition 4: To simplify, we will use $L$ to represent $L^{e}$. At date $t=0$, we have

$$
K_{0}+K_{0}^{*}=\tilde{K}_{0}+\tilde{K}_{0}^{*}
$$

With integration we have

$$
\frac{\tilde{L}_{0}}{\tilde{K}_{0}}=\frac{\tilde{L}_{0}^{*}}{\tilde{K}_{0}^{*}}=\frac{\tilde{L}_{0}+\tilde{L}_{0}^{*}}{\tilde{K}_{0}+\tilde{K}_{0}^{*}} .
$$

Denote $\lambda_{t}=\frac{K_{t}}{K_{t}+K_{t}^{*}}$ for $t=1,2, \cdots$. Since at date $t_{0}, L_{0}=\tilde{L}_{0}$ and $L_{0}^{*}=\tilde{L}_{0}^{*}$ are given, we can write:

$$
\frac{\tilde{L}_{0}}{\tilde{K}_{0}}=\frac{\tilde{L}_{0}+\tilde{L}_{0}^{*}}{\tilde{K}_{0}+\tilde{K}_{0}^{*}}=\frac{L_{0}+L_{0}^{*}}{K_{0}+K_{0}^{*}}=\frac{L_{0}}{K_{0}+K_{0}^{*}}+\frac{L_{0}^{*}}{K_{0}+K_{0}^{*}}=\lambda_{0} \frac{L_{0}}{K_{0}}+\left(1-\lambda_{0}\right) \frac{L_{0}^{*}}{K_{0}^{*}}
$$

or:

$$
\frac{L_{0}+L_{0}^{*}}{K_{0}+K_{0}^{*}}=\lambda_{0} \frac{L_{0}}{K_{0}}+\left(1-\lambda_{0}\right) \frac{L_{0}^{*}}{K_{0}^{*}}
$$

Therefore, by the concavity of the production function:

$$
\begin{gathered}
\frac{Q_{0}+Q_{0}^{*}}{K_{0}+K_{0}^{*}}=\lambda_{0} F\left(1, \frac{L_{0}}{K_{0}}\right)+\left(1-\lambda_{0}\right) F\left(1, \frac{L_{0}^{*}}{K_{0}^{*}}\right) \\
<F\left(1, \lambda_{0} \frac{L_{0}}{K_{0}}+\left(1-\lambda_{0}\right) \frac{L_{0}^{*}}{K_{0}^{*}}\right)=F\left(1, \frac{\tilde{L}_{0}}{\tilde{K}_{0}}\right)=F\left(1, \frac{\tilde{L}_{0}^{*}}{\tilde{K}_{0}^{*}}\right)
\end{gathered}
$$


Thus,

$$
\frac{Q_{0}+Q_{0}^{*}}{K_{0}+K_{0}^{*}}<\frac{\tilde{Q}_{0}}{\tilde{K}_{0}}=\frac{\tilde{Q}_{0}^{*}}{\tilde{K}_{0}^{*}}=\frac{\tilde{Q}_{0}+\tilde{Q}_{0}^{*}}{\tilde{K}_{0}+\tilde{K}_{0}^{*}}
$$

However, since $K_{0}+K_{0}^{*}=\tilde{K}_{0}+\tilde{K}_{0}^{*}$, then $Q_{0}+Q_{0}^{*}<\tilde{Q}_{0}+\tilde{Q}_{0}^{*}$. From (41), this implies that $\int_{\Omega}\left[y_{0}(\omega)+y_{0}^{*}(\omega)\right] d \mu(\omega)<\int_{\Omega}\left[\tilde{y}_{0}(\omega)+\tilde{y}_{0}^{*}(\omega)\right] d \mu(\omega)$. Therefore, from (40), $K_{1}+K_{1}^{*}<\tilde{K}_{1}+\tilde{K}_{1}^{*}$. But since aggregate effective human capital is unaffected by capital markets integration we obtain:

$$
\frac{Q_{1}+Q_{1}^{*}}{K_{1}+K_{1}^{*}}=\lambda_{1} F\left(1, \frac{L_{1}}{K_{1}}\right)+\left(1-\lambda_{1}\right) F\left(1, \frac{L_{1}^{*}}{K_{1}^{*}}\right)<F\left(1, \lambda_{1} \frac{L_{1}}{K_{1}}+\left(1-\lambda_{1}\right) \frac{L_{1}^{*}}{K_{1}^{*}}\right)=F\left(1, \frac{L_{1}+L_{1}^{*}}{K_{1}+K_{1}^{*}}\right)
$$

Rewriting this expression:

$$
Q_{1}+Q_{1}^{*}<F\left(K_{1}+K_{1}^{*}, L_{1}+L_{1}^{*}\right)<F\left(\tilde{K}_{1}+\tilde{K}_{1}^{*}, \tilde{L}_{1}+\tilde{L}_{1}^{*}\right)
$$

Dividing both sides by $\tilde{K}_{1}+\tilde{K}_{1}^{*}$ :

$$
\frac{Q_{1}+Q_{1}^{*}}{\tilde{K}_{1}+\tilde{K}_{1}^{*}}<F\left(1, \frac{\tilde{L}_{1}+\tilde{L}_{1}^{*}}{\tilde{K}_{1}+\tilde{K}_{1}^{*}}\right)=F\left(1, \frac{\tilde{L}_{1}}{\tilde{K}_{1}}\right)=F\left(1, \frac{\tilde{L}_{1}^{*}}{\tilde{K}_{1}^{*}}\right)=\frac{\tilde{Q}_{1}}{\tilde{K}_{1}}=\frac{\tilde{Q}_{1}^{*}}{\tilde{K}_{1}^{*}}=\frac{\tilde{Q}_{1}+\tilde{Q}_{1}^{*}}{\tilde{K}_{1}+\tilde{K}_{1}^{*}}
$$

Hence, $Q_{1}+Q_{1}^{*}<\tilde{Q}_{1}+\tilde{Q}_{1}^{*}$ which again from (41) and (40) implies that $K_{2}+K_{2}^{*}<$ $\tilde{K}_{2}+\tilde{K}_{2}^{*}$. This process continues for all $t=2,3,4, \cdots$ proving our claim that $Q_{t}+Q_{t}^{*}<\tilde{Q}_{t}+\tilde{Q}_{t}^{*}$. (Q.E.D.)

Proof of Proposition 5: In this framework, the inequality in incomes originates from inequality in human capital distribution since the same wage rate multiplies $h_{t}(\omega)$ [see (46) and (49)]. International capital mobility will rewult in equal wages in both countries. However, there is no effect on the optimal choices of labor supply and of parental investment in their education, namely, $l_{t}(\omega)$ and $e_{t}(\omega)$ will not vary. This can be verified directly from $(20),(21)$ and (19). Given $h_{t}(\omega), l_{t}(\omega)$ and $e_{t}(\omega), h_{t+1}$ will not vary as we change $w_{t+1}$ as well. Therefore, the human capital accumulation process will not vary and the sets $A_{t}$ will not as well [see (25)]. Using (48) and (50) we can verify that, following the changes in wage rate, the distribution of $y_{t+1}(\omega)$ will not change for $t=0,1,2, \cdots$. (Q.E.D.)

Proof of Proposition 6: Using (20), (21), (23) and (24) we rewrite (22) as follows:

$$
y_{t+1}(\omega)=C_{t}\left[4 h_{t}^{v}(\omega)+4\left(\frac{\beta_{2}}{\beta_{1}}\right) e_{g t} \bar{l}_{t} \bar{h}_{t}^{\eta}+\left(\frac{\beta_{2}}{\beta_{1}}\right)^{2} \frac{\left(e_{g t} \bar{l}_{t} \bar{h}_{t}^{\eta}\right)^{2}}{h_{t}^{v}(\omega)}\right] \quad \text { for } \omega \notin A_{t}
$$




$$
y_{t+1}(\omega)=C_{t}\left[\frac{2}{\alpha_{1}+\alpha_{2}+\alpha_{4}}\left(\frac{\beta_{2}}{\beta_{1}}\right) e_{g t} \bar{l}_{t} \bar{h}_{t}^{\eta}\right] \quad \text { for } \omega \in A_{t}
$$

Similarly,

$$
\begin{gathered}
y_{t+1}^{*}(\omega)=C_{t}^{*}\left[4 h_{t}^{* v}(\omega)+4\left(\frac{\beta_{2}}{\beta_{1}}\right) e_{g t} \bar{l}_{t}^{*} \bar{h}_{t}^{* \eta}+\left(\frac{\beta_{2}}{\beta_{1}}\right)^{2} \frac{\left(e_{g t} \bar{l}_{t}^{*} \bar{h}_{t}^{* \eta}\right)^{2}}{h_{t}^{* v}(\omega)}\right] \quad \text { for } \omega \notin A_{t}^{*} \\
y_{t+1}^{*}(\omega)=C_{t}^{*}\left[\frac{2}{\alpha_{1}+\alpha_{2}+\alpha_{4}}\left(\frac{\beta_{2}}{\beta_{1}}\right) e_{g t} \bar{l}_{t}^{*} \bar{h}_{t}^{* \eta}\right] \quad \text { for } \omega \in A_{t}^{*}
\end{gathered}
$$

where $C_{t}$ and $C_{t}^{*}$ are some positive constants. Since $h_{0}$ and $h_{0}^{*}$ are equally distributed, the same holds for $h_{0}^{v}(\omega)$ and $\left[h_{0}^{*}(\omega)\right]^{v}$. Moreover, since $\bar{h}_{0}<\bar{h}^{*}$, we obtain from (23) that $h_{1}^{*}(\omega)$ is more equal than $h_{1}(\omega)$ [see, Lemma 2 in Karni and Zilcha (1994)]. Also from $(23)$ we have that $h_{1}(\omega)$ are lower than $h_{1}^{*}(\omega)$ for all $\omega$.

Note that since:

$$
y_{1}^{*}(\omega)=C_{0}^{*}\left[\frac{2}{\alpha_{1}+\alpha_{2}+\alpha_{4}}\left(\frac{\beta_{2}}{\beta_{1}}\right) e_{g 0} \bar{l}_{0}^{*} \bar{h}_{0}^{* \eta}\right] \quad \text { for } \omega \in A_{0}^{*}
$$

and

$$
y_{1}(\omega)=C_{0}\left[\frac{2}{\alpha_{1}+\alpha_{2}+\alpha_{4}}\left(\frac{\beta_{2}}{\beta_{1}}\right) e_{g 0} \bar{l}_{0} \bar{h}_{0}^{\eta}\right] \quad \text { for } \omega \in A_{0}
$$

and on these sets $y_{1}^{*}(\omega)>y_{1}(\omega)$, the above argument is not affected by the existence of $A_{0}$ and $A_{0}^{*}$ with positive measure. In particular, we obtain that $\left[h_{1}^{*}(\omega)\right]^{v}$ is more equal than $\left[h_{1}(\omega)\right]^{v}$ [see Theorem 3.A.5. in Shaked and Santikumar (1994)]. Also we have $\left[\bar{h}_{1}\right]^{\eta}<\left[\bar{h}_{1}^{*}\right]^{\eta}$. Using (23) this implies that $h_{2}^{*}(\omega)$ is more equal than $h_{2}(\omega)$. It is easy to see that this process can be continued to generalize for all periods. (Q.E.D.)

Proof of Proposition 8: We start by showing that in each generation, individuals with higher level of human capital choose at the optimum, higher level of time to be allocated for private education of their offspring. This is clear from (19). Next we will show that such a property generates less inequality in the distribution of $y_{t+1}(\omega)$ compared to $y_{t}(\omega)$. We apply $(22)$, which represents the period $t+1$ income $y_{t+1}(\omega)$ as a function of the date $t$ income $y_{t}(\omega)$ via the human capital evolution.

Define the function $Q: R \rightarrow R$ such that $Q\left[h_{t}(\omega)\right]=h_{t+1}(\omega)$ using $(23)$ whenever $\omega \in A_{t}$, that is,

$$
Q\left[h_{t}(\omega)\right]=\left[\frac{\alpha_{3}}{\alpha_{1}+\alpha_{2}+\alpha_{3}+\alpha_{4}}\right] \theta_{t}(\omega)\left[2 \beta_{1} h_{t}^{v}(\omega)+\beta_{2} \tau_{t} \bar{l}_{t} \bar{h}_{t}^{\eta}\right]
$$


and when $\omega \in A_{t}$, this function is defined using (24) by:

$$
Q\left[h_{t}(\omega)\right]=\beta_{2} \theta_{t}(\omega) \tau_{t} \bar{l}_{t} \bar{h}_{t}^{\eta}
$$

This function is monotone non-decreasing and satisfies $Q(x)>0$ for any $x>0$ and $\frac{Q(x)}{x}$ is decreasing in $x$. Therefore [see Shaked and Shantikumar (1999)], the human capital distribution $h_{t+1}(\omega)$ is more equal than the distribution in date $t, h_{t}(\omega)$. This implies that $y_{t+1}(\omega)$ is more equal than $y_{t}(\omega)$. (Q.E.D.)

To prove the second part, it is sufficient to assume that $e_{t}(\omega)>0$ for all $\omega \in$ $G_{t}$. When this is not the case, raising $e_{g t}$ entails higher income for all low income individuals $\omega \in A_{t}$ which only reinforces the claim. Let us consider (1) for $t=0$. Since $h_{0}(\omega)$ and $l_{0}(\omega)$ are given, $h_{t}^{v}(\omega), \bar{l}_{0}$ and $\bar{h}_{0}$ are fixed. By raising $e_{g} 0$, the distribution of the human capital for generation $1, h_{1}(\omega)$, becomes more equal. This follows from Lemma 1 in Karni and Zilcha (1995). Moreover, we claim from (23) that the average human capital in generation 1 increases as well. Increasing $e_{g 0}$ will result in higher $h_{1}(\omega)$ for all $\omega$ and higher levels of $\bar{l}_{1}$ and $\bar{h}_{1}$. Moreover, it also implies that $h_{1}^{v}(\omega)$ will have a more equal distribution [see Shaked and Shanthikumar (1994), Theorem 3.A.5].

Now, let us consider $t=1$. Increasing $e_{g 1}$ will imply $\beta_{2} e_{g 1} \bar{l}_{1} \bar{h}_{1}^{\eta}$ is larger than its value before we increased the level of public education. Using (23) and the same lemma as before we obtain that $h_{2}(\omega)$ becomes more equal. This process can be continued for $t=2,3,4, \cdots$, which establishes our claim. Now, let us consider the set of families with $e_{t}(\omega)=0$. To simplify our argument assume that initially $e_{g 0}=0$, then as $e_{g 0}$ increases $h_{1}(\omega)$ will be equal or larger than in the private provision case for all $\omega \in G_{1}$ where $\omega \in A_{0}$. This fact certainly reinforces the proof of our earlier case since at the lower tail of the distribution of income, we raised and equalized the income for all $\omega \in G_{1}$ where $\omega \in A_{0}$. This process can be continued for all generations. (Q.E.D.)

Proof of Proposition 9 part (a): Let the initial distribution of human capital $h_{0}(\omega)$ be given. We compare two equilibria from the same initial conditions: one with the human capital process given by (1) and another with the same process but $\beta_{2}$ is replaced by a larger coefficient $\beta_{2}^{*}>\beta_{2}$. $\beta_{1}$ is kept unchanged. Consider again 
the following:

$$
\begin{gathered}
y_{t+1}(\omega)=C_{t}\left[4 h_{t}^{v}(\omega)+4\left(\frac{\beta_{2}}{\beta_{1}}\right) e_{g t} \bar{l}_{t} \bar{h}_{t}^{\eta}+\left(\frac{\beta_{2}}{\beta_{1}}\right)^{2} \frac{\left(e_{g t} \bar{l}_{t} \bar{h}_{t}^{\eta}\right)^{2}}{h_{t}^{v}(\omega)}\right] \quad \text { for } \omega \notin A_{t} \\
y_{t+1}(\omega)=C_{t}\left[\frac{2}{\alpha_{1}+\alpha_{2}+\alpha_{4}}\left(\frac{\beta_{2}}{\beta_{1}}\right) e_{g t} \bar{l}_{t} \bar{h}_{t}^{\eta}\right] \quad \text { for } \omega \in A_{t} \\
y_{t+1}^{*}(\omega)=C_{t}^{*}\left[4 h_{t}^{* v}(\omega)+4\left(\frac{\beta_{2}^{*}}{\beta_{1}}\right) e_{g t} \bar{l}_{t}^{*} \bar{h}_{t}^{* \eta}+\left(\frac{\beta_{2}^{*}}{\beta_{1}}\right)^{2} \frac{\left(e_{g t} \bar{l}_{t}^{*} \bar{h}_{t}^{* \eta}\right)^{2}}{h_{t}^{* v}(\omega)}\right] \quad \text { for } \omega \notin A_{t}^{*} \\
y_{t+1}^{*}(\omega)=C_{t}^{*}\left[\frac{2}{\alpha_{1}+\alpha_{2}+\alpha_{4}}\left(\frac{\beta_{2}^{*}}{\beta_{1}}\right) e_{g t} \bar{l}_{t}^{*} \bar{h}_{t}^{* \eta}\right] \quad \text { for } \omega \in A_{t}^{*}
\end{gathered}
$$

where $C_{t}$ and $C_{t}^{*}$ are some possible constants. Since $h_{0}(\omega)$ is fixed at date $t=0$, we find [see, Lemma 2 from Karni and Zilcha (1994)] that $\frac{\beta_{2}^{*}}{\beta_{1}}>\frac{\beta_{2}^{*}}{\beta_{1}}$ imply that $y_{1}^{*}(\omega)$ is more equal to $y_{1}(\omega)$. We also derive that $h_{1}(\omega)$ are lower than $h_{1}^{*}(\omega)$ for all $\omega$, and hence, $\bar{h}_{1}<\bar{h}_{1}^{*}$. This inequality reinforces the result when $\mu\left(A_{0}\right)>0$. By $(23), h_{1}^{* v}(\omega)$ is more equal than $h_{1}^{v}(\omega)$ and $4\left(\frac{\beta_{2}^{*}}{\beta_{1}}\right) e_{g t} \bar{l}_{t}^{*} \bar{h}_{t}^{* \eta}+\left(\frac{\beta_{2}^{*}}{\beta_{1}}\right)^{2} \frac{\left(e_{g t} \bar{l}_{l}^{*} \bar{h}_{t}^{* \eta}\right)^{2}}{h_{t}^{* v}(\omega)}>$ $4\left(\frac{\beta_{2}}{\beta_{1}}\right) e_{g t} \bar{l}_{t} \bar{h}_{t}^{\eta}+\left(\frac{\beta_{2}}{\beta_{1}}\right)^{2} \frac{\left(e_{g t} \bar{l}_{t} \bar{h}_{t}^{\eta}\right)^{2}}{h_{t}(\omega)}$, hence $h_{2}^{*}(\omega)$ is more equal than $h_{2}(\omega)$. This same argument can be continued for all dates $t=3,4,5, \cdots$ Also note that $A_{t} \subset A_{t}^{*}$ (where $A_{t}^{*}$ is the set of families in $G_{t}^{*}$ who choose $e_{t}(\omega)=0$ ) since $4\left(\frac{\beta_{2}^{*}}{\beta_{1}}\right) e_{g t} \bar{l}_{t}^{*} \bar{h}_{t}^{* \eta}+$ $\left(\frac{\beta_{2}^{*}}{\beta_{1}}\right)^{2} \frac{\left(e_{g t} \bar{l}_{l_{t}}^{*} h_{t}^{* \eta}\right)^{2}}{h_{t}^{* v}(\omega)}>4\left(\frac{\beta_{2}}{\beta_{1}}\right) e_{g t} \bar{l}_{t} \bar{h}_{t}^{\eta}+\left(\frac{\beta_{2}}{\beta_{1}}\right)^{2} \frac{\left(e_{g t} \bar{l}_{t} \bar{h}_{t}^{\eta}\right)^{2}}{h_{t}^{t}(\omega)}$ for all $t$. This only contributes to the more equal distribution of $y_{t+1}^{*}(\omega)$ since the left hand tail has been increased and equalized compared to the $y_{t+1}(\omega)$ case. To complete the proof, consider the case where we increase $\eta$. When we increase the value of $\eta$, keeping other parameters constant, we are basically increasing the second term in $(23), \bar{h}_{0}^{\eta}$ while $h_{0}^{v}(\omega)$ remains unchanged. Again by Lemma 2 in Karni and Zilcha (1994), we obtain that the distribution of $h_{1}(\omega)$ becomes more equal. Taking into account the families $\omega \in G_{1}$ who belong to $A_{0}$ (i.e., the lower tail of the distribution of income) only reinforces the higher equality since their incomes are uniformly increased, while for all other $\omega \in G_{1}, \omega \notin A_{0}$, the proportional raise in their income is smaller. This can be continued for $t=2$ as well since it is easy to verify that $\bar{h}_{1}^{\eta}$ increases while $h_{1}^{v}(\omega)$ becomes more equal. Now this process can be extended to $t=2,3, \cdots$, which completes the proof. (Q.E.D.)

Proof of Proposition 9 part (b): The proof of part (b) follows from the same types of arguments using the fact that if $\beta_{1}<\beta_{1}^{*}$ then $\frac{\beta_{2}}{\beta_{1}}>\frac{\beta_{2}}{\beta_{1}^{*}}$, and hence $h_{1}(\omega)$ 
is more equal then $h_{1}^{*}(\omega)$ and $\bar{h}_{1}>\bar{h}_{1}^{*}$. This process leads, using similar arguments as before, to $y_{t}(\omega)$ more equal than $y_{t}^{*}(\omega)$ for all periods $t$. To complete the proof, we compare two economies which differ only in parameter $v$. The economy with higher $v$ will have more inequality in the intragenerational income distribution in all periods. This can be seen as follows. Since the two economies have the same initial distribution of human capital $h_{0}(\omega)$, the process that determines $h_{1}(\omega)$ differs only in the parameter $v$. Denote by $v^{*}<v \leq 1$ the parameters, then it is clear that $\left[h_{0}(\omega)\right]^{v^{*}}$ is more equal than $\left[h_{0}(\omega)\right]^{v}$ since it is attained by a strictly concave transformation [see, Shaked and Shanthikumar (1994)]. Likewise, the human capital distribution $h_{1}^{*}(\omega)$ is more equal than the distribution $h_{1}(\omega)$. This implies that $y_{1}^{*}(\omega)$ is more equal than $y_{1}(\omega)$. Now we can apply the same argument to date 1: the distribution of $\left[h_{1}^{*}(\omega)\right]^{v^{*}}$ is more equal than that of $\left[h_{1}(\omega)\right]^{v^{*}}$, and hence, using (23) and the above reference, we derive that the distribution of $\left[h_{2}^{*}(\omega)\right]^{v^{*}}$ is more equal than that of $\left[h_{2}(\omega)\right]^{v^{*}}$. The process can be continued for all t. (Q.E.D.)

Proof of Proposition 9 part (c): From (23) we see that inequality in the distribution of $h_{1}(\omega)$ remains unchanged even though all levels of $h_{1}(\omega)$ increase due to this technological improvement. In particular, $\bar{h}_{1}$ increases. Now, since inequality of $h_{1}^{v}(\omega)$ did not vary but the second term in the right hand side of (23) has increased due to the higher value of $\bar{h}_{1}$, we obtain more equal distribution of $h_{2}(\omega)$. When $\mu\left(A_{0}\right)>0$, the higher $\bar{h}_{1}$ results in higher income to all $\omega \in G_{1}$ who belong to $A_{0}$, which only reinforces the more equality in $y_{2}^{*}(\omega)$. Now, this argument can be used again at dates $3,4, \cdots$ which completes the proof. (Q.E.D.) 


\section{References}

Acemoglu, D. (2003), Cross-country inequality trends, Economic Journal 113, F121F149.

Adelman, M. and U. Morris (1973), Economic Growth and Social Equity in Developing Countries, Stanford: Stanford University Press.

Atkinson, A.B. (1999), Is rising income inequality inevitable? A critique of the Transatlantic consensus, UNU/WIDER.

Barro, R.J., J.W. Lee (2001), Schooling quality in a cross-section of countries, Economica 68, 465-488.

Becker, G.S. and B.R. Chiswick (1966), Education and the distribution of earnings, American Economic Review 86, 218-223.

Benabou, R. (1996), Equity and efficiency in human capital investment: the local connection, Review of Economic Studies 63, 237-264.

Bougheas, S. and R. Riezman (2005), Trade and the distribution of human capital, CESifo Working Paper 1475.

Burnhill, P., C. Garner and A. McPherson (1990), Parental education, social class and entry to higher education 1976-86, Journal of the Royal Statistical Association, Series A, 153, 233-248.

Brunello, G. and D. Checchi (2005), School quality and family background in Italy, Economics of Education Review 24, 563-577.

Chenery, H.B. and M. Syrquin (1975), Patterns of Development, 1950-1970, London: Oxford University Press.

Chiswick, B.R. (1971), Earnings inequality and economic development, Quarterly Journal of Economics 85, 21-39.

Chiu, H. (1998), Income inequality, human capital accumulation and economic performance, Economic Journal 108, 44-59.

Corneo, G. and O. Jeanne (2001), Status, the distribution of wealth, and growth, Scandinavian Journal of Economics, 103, 283-293. 
Eckstein Z. and I. Zilcha (1994), The effects of compulsory schooling on growth, income distribution and welfare, Journal of Public Economics 54, 339-359.

Fernandez, R. and R. Rogerson (1998), Public education and income distribution: a quantitative dynamic evaluation of education-finance reform, American Economic Review 88, 813-833.

Fischer, R.D. and P.J. Serra (1996), Income convergence within and between countries, International Economic Review 37, 531-551.

Glaeser, E.L. (1994), Why does schooling generate economic growth?, Economics Letters 44, 333-337.

Hanushek, E.A. (1986), The economics of schooling: production and efficiency in public schools, Journal of Economic Literature 24, 1141-1177.

Hanushek, E.A. (2002), Publicly provided education, in: A. Auerbach and M. Feldstein (eds.), Handbook of Public Economics, Amsterdam: North Holland.

Karni, E. and I. Zilcha (1994), Technological progress and income inequality: a model with human capital and bequests, in J. Bergstrand et al. (eds.), The Changing Distribution of Income in an Open US Economy, Amsterdam: North Holland, 279-297.

Laitner, J. (1997), Intergenerational and interhousehold economic links, in: M.R. Rosenzweig and O. Stark (eds.), Handbook of Population and Family Economics, Amsterdam: North Holland.

Leamer, E. and J. Levinsohn (1995), International trade theory: the evidence, in: G. Grossman and K. Rogoffs (eds.), Handbook of International Economics III, Amsterdam: North-Holland.

Leiderman, L. and A. Razin (1994), Capital Mobility: The Impact on Consumption, Investment and Growth, Cambridge University Press, Cambridge.

Maddison, A. (1991), Dynamic forces in capitalist development: a long-run comparative view, Oxford: Oxford University Press.

Orazem, P. and L. Tesfatsion (1997), Macrodynamic implications of income-transfer policies for human capital investment and school effort, Journal of Economic 
Growth 2, 305-329.

Shaked, M. and J.G. Shanthikumar, Stochastic Orders and Their Applications, Boston: Academic Press.

Tamura, R. (1991), Income convergence in an endogenous growth model, Journal of Political Economy 99, 522-540.

Viaene, J.-M., and Zilcha, I. (2003), Human Capital Formation and Cross-Country Comparison of Inequality, Mimeo, Erasmus University Rotterdam.

Wharton, A. S. and M. Blair-Loy (2006), Long Work Hours and Family Life, Jounral of Family Issues 27, 415-436. 